\title{
The Costume in the Earliest Chinese Hand Scroll
}

\author{
Yue $\mathrm{Hu}$ \\ Fashion Art Design Institute, Donghua University \\ Shanghai, 200051, China \\ Fashion College, Shanghai University of Engineering Science \\ Shanghai, 201620, China \\ E-mail: huyue2006_1@126.com
}

\begin{abstract}
The earliest Chinese hand scroll extant painting is the 'Nushi zhen' by Gu Kaizhi housed in the British Museum, which is now often considered to be a Tang Dynasty copy of the original. By compared with correlated literatures and images, the typical skill and styles in which the earliest Chinese figure painters of Jin Dynasty (AD 265-420) depicting costumes is opened out, as well as the typical costume patterns and styles of man, woman and children.
\end{abstract}

Keywords: Costume, Hand scroll, 'Nushi zhen', Gu Kaizhi

In South Qi Dynasty (AD 479-502) of Southern Dynasties, Xie He said: "No ancient painting is exquisite until Wei Xie." in his <Commentaries on Ancient Paintings>. The ancient paintings Xie mentioned were the Chinese handscroll paintings of figure illustrations, and Wei was famous in Western Jin Dynasty (AD 265-317). So the mature style of Chinese ancient handscroll painting should appear from then on. Unfortunately, there was no Wei's painting in existence, even copies. The earliest painting we can see nowadays is the 'Nushi zhen' by Gu Kaizhi housed in the British Museum, who was a top painter of the Eastern Jin Dynasty (AD 317-420), and ever learned painting from Xie. Upon that, this article will study the representation of garment and accessories of the figures in the painting all-sided. And by comparing with correlated literature and images, it may unveil the prevailing skills and styles of earliest Chinese handscroll figure painting at that time, although the painting being likely a later copy.

\section{Gu Kaizhi and his works}

Gu Kaizhi, (AD 345-407), a native of Wuxi in Jiangsu province, gained a reputation as a painter at the Jin court in Nanjing. He was famous for his portraits and figures, but he also painted landscapes. A number of important paintings are attributed to him, such as 'Nushi zhen', 'Nymph of the Luo River', 'Ladies of Beneficent \& Wise in History', 'Chop Guqin', etc. But they were not associated to him in texts until the Song dynasty, so the relationship to him is tenuous.

According to the literature, Zhang Yanyuan of Tang Dynasty said: "Gu's brushwork was compact, immediate, continuous, circular, fast like wind and thunder.” in <The Records \& Commentaries on Historical Famous Paintings>. Tang Hou of Yuan Dynasty also said that his paintings looked like the silk spun by spring silkworm, the cloud floating in the sky and the stream gliding on the ground, in his $<$ Discrimination of Paintings $>$. Then we now know the probable style of $G u$ 's drawing. Comparing with other paintings in his name, the 'Nushi zhen' housed in the British Museum is the proximal copy to those literatures, so it is authentic for us to study the representation of garment and accessories of the figures in the earliest Chinese handscroll paintings.

The handscroll 'Nushi zhen' (also called “Admonitions of the Instructress of the Ladies in the Palace”) (see Figure-1)illustrates a moralising text by Zhang Hua (AD 232-300) which discusses the correct behaviour of ladies of the imperial harem. The scroll consists of quotations from the text, followed in each case by figure illustrations without any background or at most slight suggestions of setting. It was made of ink and coloured on silk, which was 343.75 centimetres long and 24.37 centimetres high. This is the finest extant work attributed to $G u$ and one of the two versions of this theme (the other is in the Palace Museum, Beijing).

There are many differences of painting styles from Han Dynasty in the handscroll. Scene seven, for example, shows a court lady advancing towards the Emperor, who was repulsing her with a gesture of his raised hand. The drapery is portrayed with long, continuous and even brushstrokes; movement is shown through the vitality of the swirling 
draperies, a continuation of Han Dynasty traditions. The facial expressions of the figures have advanced beyond the generalised types of Han figures; the characterisation of facial expression here is closer to portraiture, displaying individual character and emotion, etc.

As the representation of garment and accessories shown in it is discussed neither in fine art nor in costume academe, the study on it is significative.

\section{Analysis of figures' apparel drawing}

The hand scroll 'Nushi zhen' depicts forty figures totally, including eighteen ladies, seventeen men, and five children. The analyses of the representation of those figures' apparel all-sided in it are as follows:

\subsection{Head ornaments}

All the ladies are ornamented with Jinjue hairpin, jointed with Buyao (it appeared in Han Dynasty, which is a kind of flower-like movable ornament on the hairpin, usually made of gold), as Figure-1 shows. The hairpin is outlined in thin ink line covered with red, while the Buyao is illustrated in quit different uneven curly red lines, which shows obvious distinctness compared with the ornament in silk painting of Mawangdui Han Tomb (see Figure-2). That makes out the advance of expressive force on lines.

There are several kinds of hat men wearing, one is the Tongtian hat which Emperor Yuan of Han worn , one is a sort of deerskin hat three men had on, one is all the housecarl and wagoner worn, named as Black Lacquered Silk hat, others are called Qia by ancient Chinese.

On the other hand, the hats were drawn in various ways. For example, the upper part of Tongtian hat was painted like ribbon, and the tie part of hat was also illustrated in two segments, with the wider line representing Ying and the thinner lines hiking up like dragon antenna representing Wei, which hinting the afeared feeling of Emperor Yuan of Han. That means the painters in Jin Dynasty had begun to use diverse lines to make a clear distinction of different apparel parts, also to concern the expression of lines and shapes to show the figure's innermost being.

And the representation of Black Lacquered Silk hat of the housecarl and wagoner tell us that the painter was able to illustrate object from diverse angle of view that time. Comparing with the paintings of Han Dynasty, it was a great advance too. Although the painting skill of texture of netlike Black Lacquered Silk derived from Han Dynasty, it showed much more delicacy and third dimension. Furthermore, the transparency was never seen before, which made the Ze (a kind of ancient cap) and the shape of head under the silk hat be seen clearly.

The men's deerskin hats showed in Figure-4 painted with stronger third dimension by two lotus-leave-like parts standing towards two directions in front of the forehead, with alternation of black and white strips. The presentation was undoubtedly superexcellent, which exceeded the anterior paintings on the stones and bricks of Han.

\subsection{Hairstyle}

The woman's hairdo in the scroll has two styles, one is a big bun worn at the back of the head, with a string of hair behind (see Figure-1), the other is hanging down, with a double-loop knot at the end of the hair. Obviously this painting style also came from Han(see Figure-3). The forms which represent the hairstyle of women differ greatly from men, which were all painted flat and sharp, like paper-cut, while the men's were illustrated vividly into threads. Although the representation of man's hair was not originated from that time, but no doubt it had shown obvious advance in the scroll by then.

\subsection{Silhouette}

It was common for women of Jin to dress short jupe with V-collar and long skirt reaching the ground with wide pleads. The silhouette of woman garments appears tight at the top and the waistline, while loose at the bottom and the cuff, which could be traced up to Chu of Eastern Zhou Dynasty (see picture-4, a piece of silk painting named "lady with dragon \& phoenix"), even the turnup skirt lap looks just the same. Although the poses and guises of the ladies in the scroll differed slightly, they all followed the shape of "L". According to the archaeological study, we know the silhouette was not formed by the garment itself, but a kind of artistic distortion by the painter of the hand scroll, which revealed the aesthetic idea that age.

The curly flying silk band of the lady's garment is another obvious feature. It could be comprehended as scarf, waistband, and Zaju (the multiple angular lap of the apron). This kind of figure shape appeared in several images of that time or later copies, such as lacquer painting in Datong Sima Jinlong Tomb of Northern Wei Dynasty (see Figure-5). It seems more like a kind of apparel representation style than the actual structures of suit-dress those days too.

As for the men and children, the silhouettes in the scroll were far more veridical compared to the lady's. There were no exaggerated shapes of garment or accessory parts in the scroll, except the robe of Emperor Yuan of Han, just like his tie of Tongtian hat, tossed about to illustrate his terrified mind. The representation was first brought forward by Gu Kaizhi in his argument on figure painting named "a form for an expression", which influenced generations of ancient Chinese painters. The point is that the painter only highlighted few figures in this way to show their difference. 


\subsection{Structure}

According to the scroll, the representation of structures of the garments, comparing men's with women's, shows more similarity than difference. The most painstaking depictions were all surrounding the head, besides the hat and the ornaments, the collar's structure was illustrated quite exquisitely, which represents more than two layers of gowns or frocks. Take the gown of man for example, the outermost one is called Danyi, which is made of gossamer, so only the edge of the collar was painted, and often right lapel on the left. The middle layer gown usually has edging on the V-collar, with left lapel on the right. The innermost one is under gown, shown by several slim lines. Moreover the women usually has furbelow around their necks.

Another important structure the scroll presenting is the waistline of figures. It seems that the men's were loose and lower, using narrow belt covered by the bulgy gown; while the women's were fairy tight and higher, often fastened with long silk band and knotted in the front. Under the lady's belt, there were usually apron and netlike cestus contracting the waist, which just as the lady's in the silk painting of East Zhou Dynasty mentioned before (see Figure-4).

Not only on the collar, but also the edging of the gown and skirt was a key part illustrated quite meticulously, which also emphasized the outline of those lumpy laps. Comparatively, the cuffs of gowns and jupes were depicted quite vaguely, with a lot of interlaced lines only to show a rough appearance of several layers of clothes. Nor did those flying curly silk band of ladies express their cause and effect as which parts of garments they were.

There is an indistinctive garment's structural detail in the scroll, which indicating the seam of the joint of sleeves to panel (like the armhole called today), appeared on quite a few figures' outermost gown (Danyi). That is to say that the painters of Jin even paid relatively more attentions on the structure of garments than later generations. It also showed that the painter then, by careful observation, tried their best to reproduce what the real garments should be on the hand scroll.

\subsection{Shoes}

It is interesting that all the men's shoes were illustrated partly or integrally, while the women's were all covered up by skirts. The representative feature is common in Han Dynasty, but not prevailing after Jin Dynasty. It still revealed that the female image in the hand scroll of Jin strongly influenced by Han, and the wearing style of shoes was covered by skirts.

On the contrary, the men's shoes could be depicted so vivid that it almost likes a rendering of sketch. It also shows the great advance on the accessory illustration of scroll painting in Jin, like later generations.

\section{Painting skills}

The painting skills the scroll expressing those garments and accessories were significant signs of Jin Dynasty, and influenced later painters for a long time.

Firstly, the lines of the scroll painted in taper brush all looks evenly narrow and slim, traveling slowly and smoothly, without diversification of strokes. This kind of line used to be called as "spring-silkworm-spitting-silk line" or "ancienthairspring line" of "eighteen outlines" in drawing garments on traditional Chinese painting. This linetype is the earliest one appeared in Chinese hand scroll figure painting, reflecting the rudiment of apparel representation, which mainly came into the style of Han. It wasn't until Tang Dynasty that more kinds of strokes began to be shaped up. But the mode of the line had also been advanced greatly by then, just as its name described by later essayists. So it demonstrated the concern of the painters on the expressive force of lines about apparel molding.

Secondly, the colors applied in the scroll were quite few, besides ink, mainly vermilion and ochre, which means the palette of inchoate scroll painting was fairy limited. Obviously these colors couldn't match all the garments and accessories wearing in historical reality. For example, the vermilion was used to paint golden head ornament, also to tinge clothes and edgings. Shortly after that time, in Southern and Northern Dynasties, more colors were painted on scroll painting, such as green, yellow, white, etc.

Thirdly, the most important feature lies that although the lines and the palettes were both monotone, the skills of the render on the garment and accessory displayed in the scroll varied wildly from flat to shade, thick to thin, even overlapping. There was almost no repeated rendering skill used on a single figure's apparel, which represented the diversity of various clothes parts. In these crack ways, the painter of that era could represent luxuriant costume colors within limited tincts.

Lastly, also because of the lack of styles of lines and colors, the painters then could show almost no pattern on those garments, even though the textile pattern of Han and Wei had taken on a gorgeous visage. So it revealed that the painting skills that time were not capable of handling those complicated apparel patterns yet. Furthermore, there are few kinds of fabric materials represented in the scroll, because of the limitation on the painting skills. 


\section{Conclusion}

By the study of the representation of garment and accessories all-sided in the 'Nushi zhen', a scene of the hand scroll figure illustrations in Jin Dynasty is depicted. It could be concluded at least six points from the analysis.

The representation of apparels in Jin Dynasty derived directly from Han Dynasty, especially on the way it painting the outer woman.

The painting showed much more delicacy and third dimension on the apparels, which represents the great advance made in Jin, especially on the men's outfit, such as hats and shoes.

The painter in Jin Dynasty has begun to concern the expressive force of apparels' lines and shapes to show the figure's innermost being.

There are few kinds of fabric materials showed in the scroll out of silk textiles, because of the limitation on the painting skills.

The rudiment of apparel representation of earliest Chinese figure illustration had been brought forth by that time, showed by the painting skill of lines, colors and rendering.

Above all, the painter of that age, by careful observation, made great efforts to reproduce what the real garments and accessories should be in the scroll.

The 'Nushi zhen' was a very important milestone of the beginning of ancient Chinese figure hand scroll painting. From then on, the representation of garment and accessories, along with the development of figure illustrations flourished for almost a thousand years till the rise of landscape in Southern Song Dynasty.

\section{References}

Tang, Hou. (1958). Discriminations of Paintings. Beijing: People’s Fine Arts Publishing House, pp.28.

Zhang, Yanyuan. (1963). The Records \& Commentaries on Historical Famous Paintings. Beijing: People’s Fine Arts Publishing House, pp.23.

Zhang, Yanyuan. (1963). The Records \& Commentaries on Historical Famous Paintings. Beijing: People's Fine Arts Publishing House, pp.109.

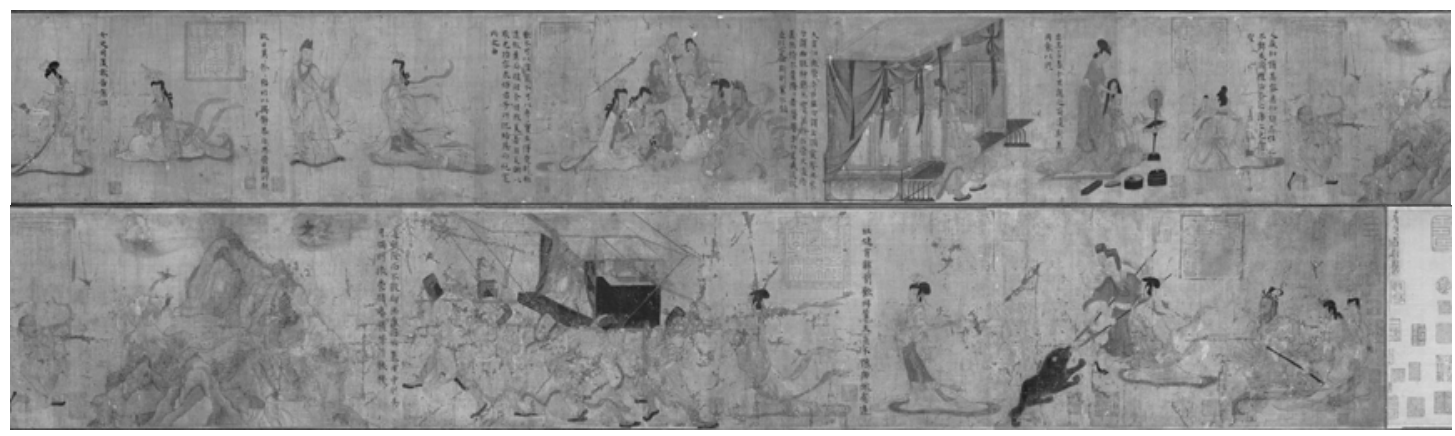

Figure 1. The earliest Chinese hand scroll named ‘Nushi zhen’ 


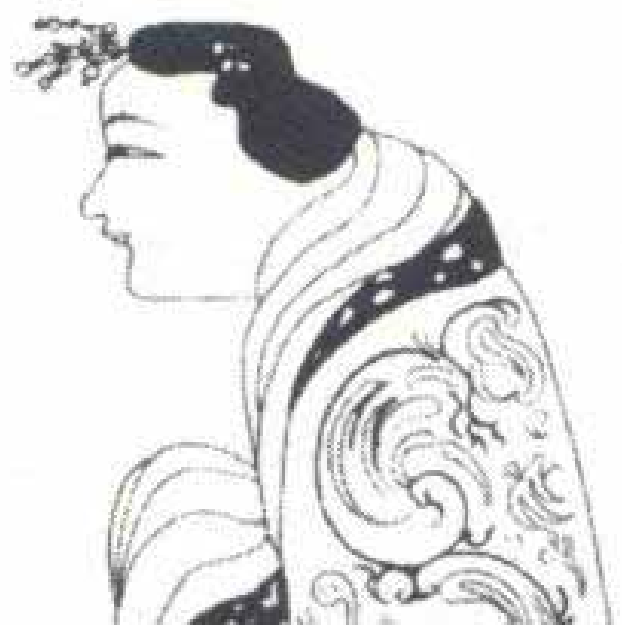

Figure 2. Lady's head ornaments and the hairstyle in silk painting of Mawangdui

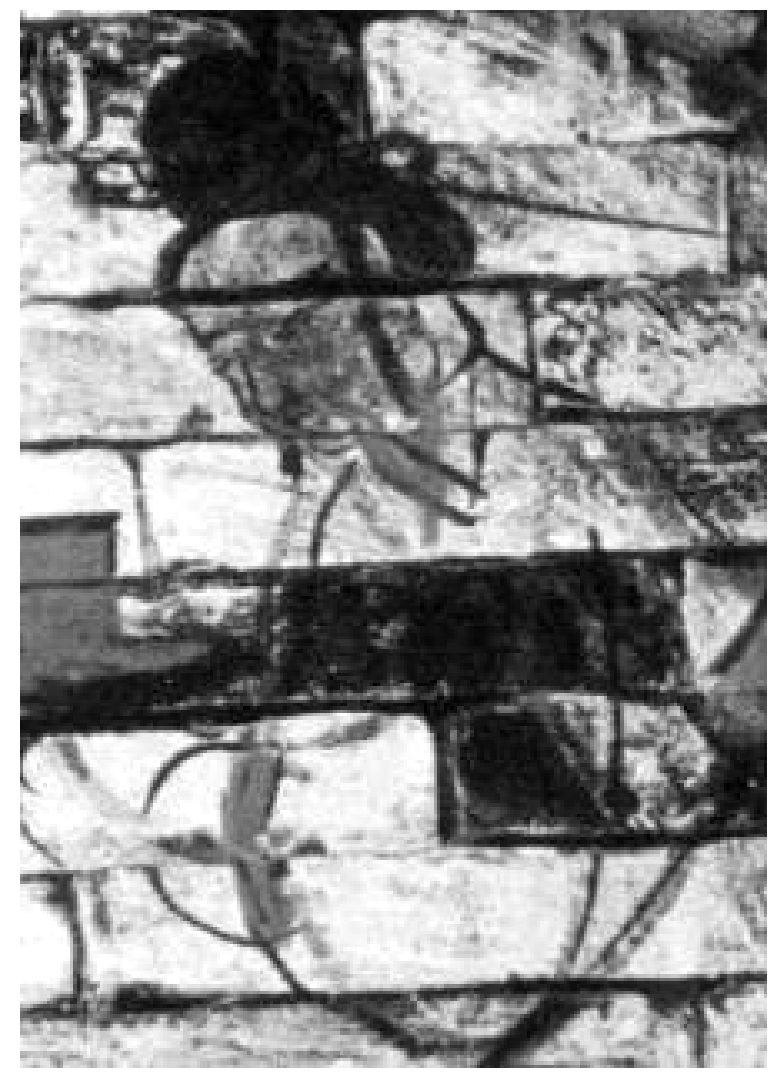

Figure 3. Figure brick in a tomb of Han Dynasty 


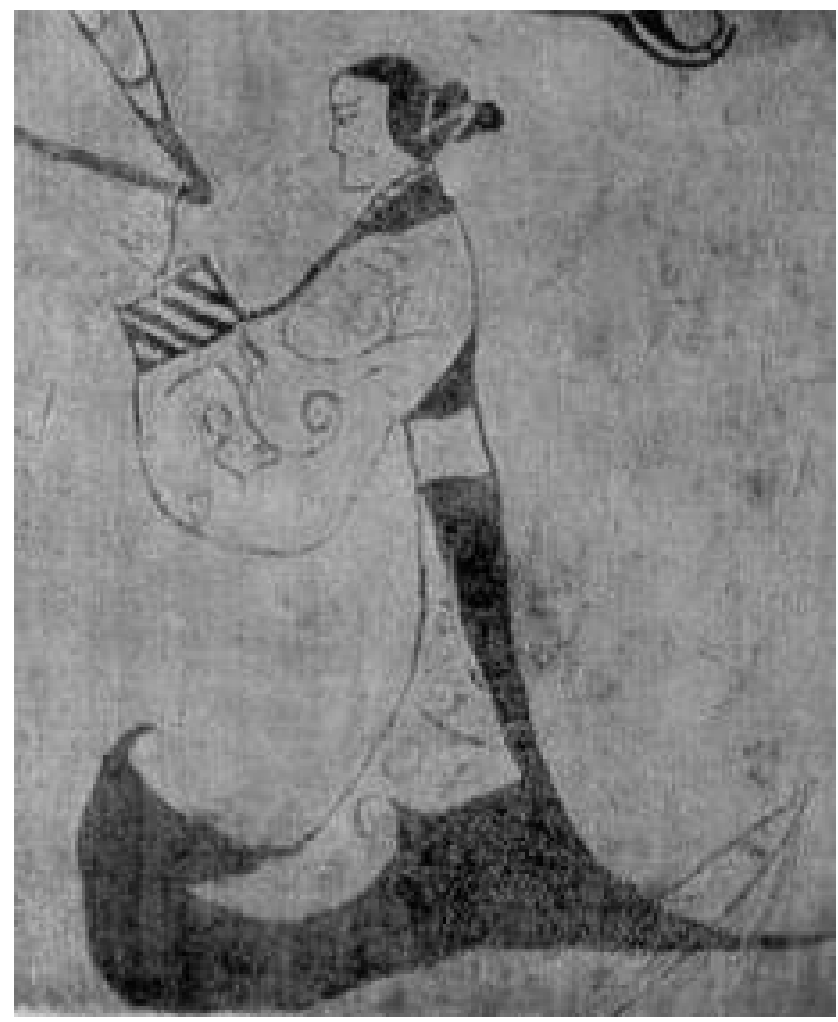

Figure 4. Lady's silhouette in the silk painting of Eastern Zhou Dynasty

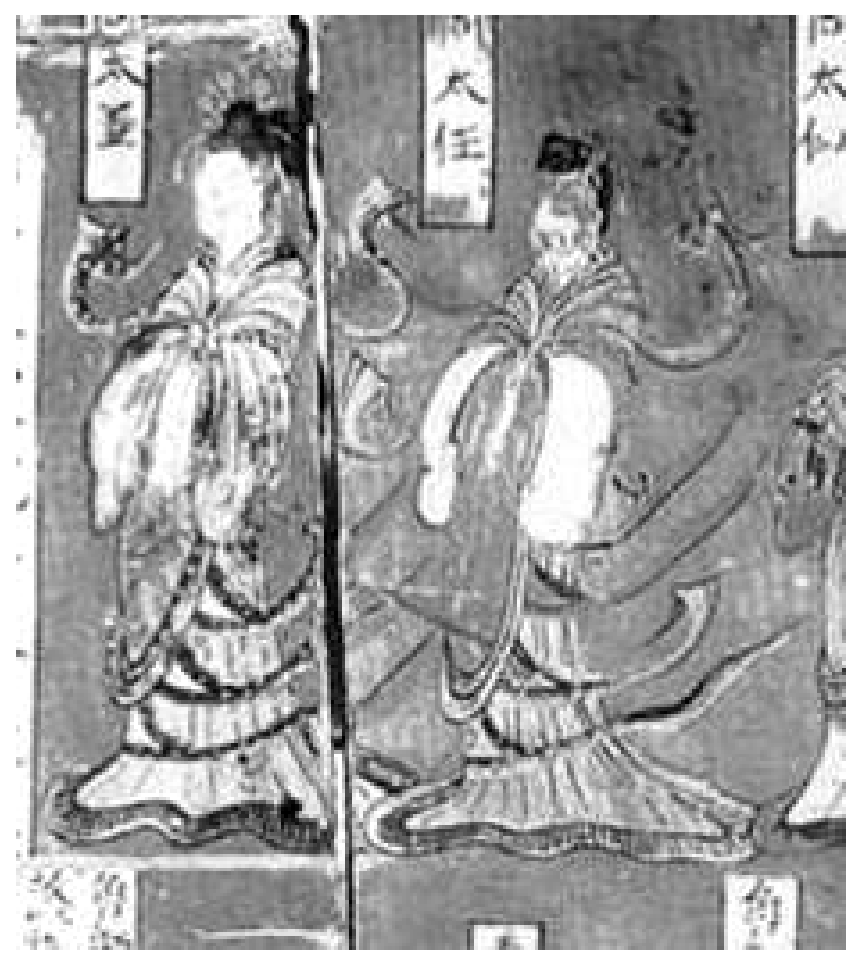

Figure 5. Lacquer painting in Datong Sima Jinlong Tomb 